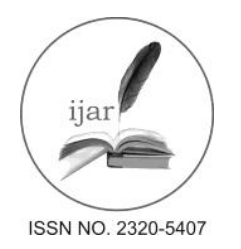

Journal homepage: http://www.journalijar.com

Journal DOI: $\underline{\text { 10.21474/IJAR01 }}$

INTERNATIONAL JOURNAL

OF ADVANCED RESEARCH

RESEARCH ARTICLE

\title{
RT.ATERIAL RHABDOMYOMA WITH SPONTANEOUS REGRRESION IN A 30-MONTHS OLD FEMELE.
}

Eman Hassn Al-Hmairy.

CABP/FICMSP, Karbala Teaching Hospital for Children,Karbala,Iraq

\section{Manuscript Info}

Manuscript History:

Received: 16 April 2016

Final Accepted: 26 May 2016

Published Online: June 2016

Key words:

Cardiac Rhabdomyoma.

*Corresponding Author

Eman Hassn Al-Hmairy.

\section{Abstract}

Primary cardiac tumors are rare in pediatric age group.most primary cardiac tumors are benign and the most common tumors are rhabdomyomas $45 \%$,fibroma $25 \%$,myxoma $10 \%$,intrapericardial teratoma $10 \%$, and hemangioma 5\%. I describe a 21 days old neonate female was dignosed with RT.aterial mass(rhabdomyomas) by echocardiography . with continous follow up for the size of the mass, that is regress spontaneously after 30 months.

This is the second case reported with rhabdomyoma and spontaneous regression in echo departement of Kabala Teaching Hospital for Children.

Copy Right,IJAR, 2016. All rights reserved.

\section{Introduction:-}

Rhabdomyoma constitute $45 \%$ to $80 \%$ of all primary cardiac tumors in the pediatric age group.these tumors can be diagnosed in the prenatal period but are most frequently diagnosed in the newborn infant.occurrences of sudden death in pediatric patients of all ages, including stillbirth,have been attributed to cardiac rhabdomyoma(4). The male to female ratio is equal(6)

Diagnosis:-

ECG ,47\% of patient with cardiac tumors have abnormal ECG,ST segment abnormalities or strain,LVH,dysrhythmia(4).

2-D doppler echocardiography as the primary diagnostic procedure for the evaluation of cardiac tumors (4).it have greater sensetivity than MRI for the detection of intramural or intracavitary cardiac tumors(4).

MRI has been used for detection of tumors,location,to differeniate vascular tumors such as cardiac heamangioma from rhabdomyoma and fibroma.

Rhabdomyoma are multiple,well circumscribed,non capsulated ,white or gray-white intramural or intracavitary nodules that can occur any where in the heart.cardiac rhabdomyoma occur as single intramural or intracavitary mass in $10 \%$ of patient.(4)

\section{Case report:-}

A 21 - days old neonate referred to echo department for echocardiography because she had soft systolic murmur at lower left sternal border on examination: temperature was $36.8 \mathrm{C}^{0}$, heart rate 148 beat per minute,respiratory rate 62 per minute 
The patient was tachypnic,no cyanosis,no pallor,no periorbital or sacral oedema,no skin pigmentation.

Chest examination was normal vesicular breathing no added sounds,heart normal first \& second heart sound with soft systolic murmur at lower left sternal border grade 2 .

\section{Abdominal examination was normal:-}

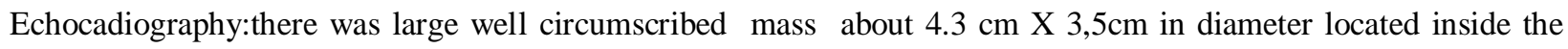
RT.aterium extending to the tricusp.valve leaflet and compressing the LT.aterium and pulmonary artery associated with severe pericardial effusion and moderate tricusp valve regurge.normal pressure gradient through aortic and pulmonary valves.

CXR:- cardiomgaly

MRI:- reveal RT.aterial rhabdomyoma

She was sent for IBN-ALBETAR hospital for pericardiocenthesis the pericardial fluid analysis was:glucose $84.8 \mathrm{mg} / \mathrm{dl}$,protein $4.30 \mathrm{gm} / \mathrm{dl}$,LDH 297,AFB negative.pericardial fluid for cytology reveal hypocellular smear showing few scattered chronic inflammatory cells,reactive mesothelial cells and histeocytes.no malignant cells was seen.

CBP:- WBC 17000 ,lymphocytes 79.4\%,Hb 10.7g/dl,platelets 418000,ESR 12.

RBS $96 \mathrm{mg} / \mathrm{dl}$,blood urea $21 \mathrm{mg} / \mathrm{dlm}$,s.creatinen $0.5 \mathrm{mg} / \mathrm{dl}$. PT $14.0 \mathrm{sec}$. ,PTT 30.0sec.,INR 1.1

She was put on prednisolon syp.and frusemide syp.for 4 weeks with gradual tapering for moderate pericardial effusion that persist after aspiration and disappear after 3 months.

She was seen by cardiothoracic surgery who advised surgical interference which postponed because it had high risk.so the patient was kept in continuous follow-up by echocardiography examination, every 4 weeks to start with and then every 2 months when she start to regress in size gradually. after 5 months the size of the mass was $3 \mathrm{~cm} \mathrm{X}$ $2 \mathrm{~cm}$.with complete regression at age 30 months .

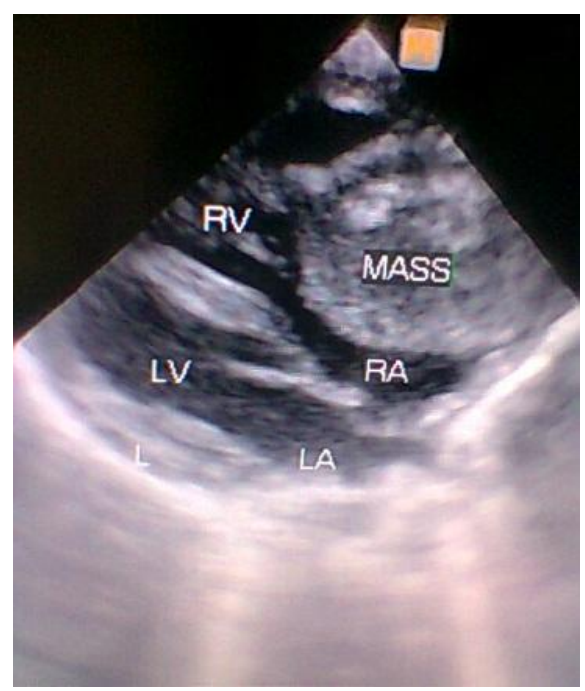

Figure 1:-

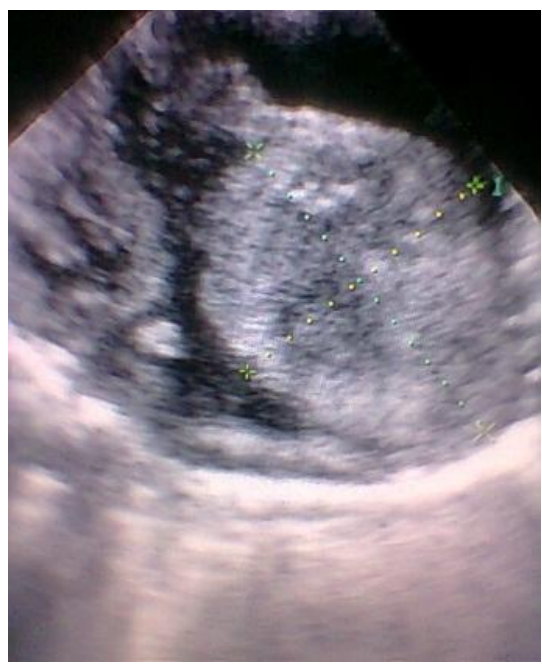

Figure 2:-

(figure 1 \& 2) -RT.aterial rhabdomyoma in 21 days days old female. 

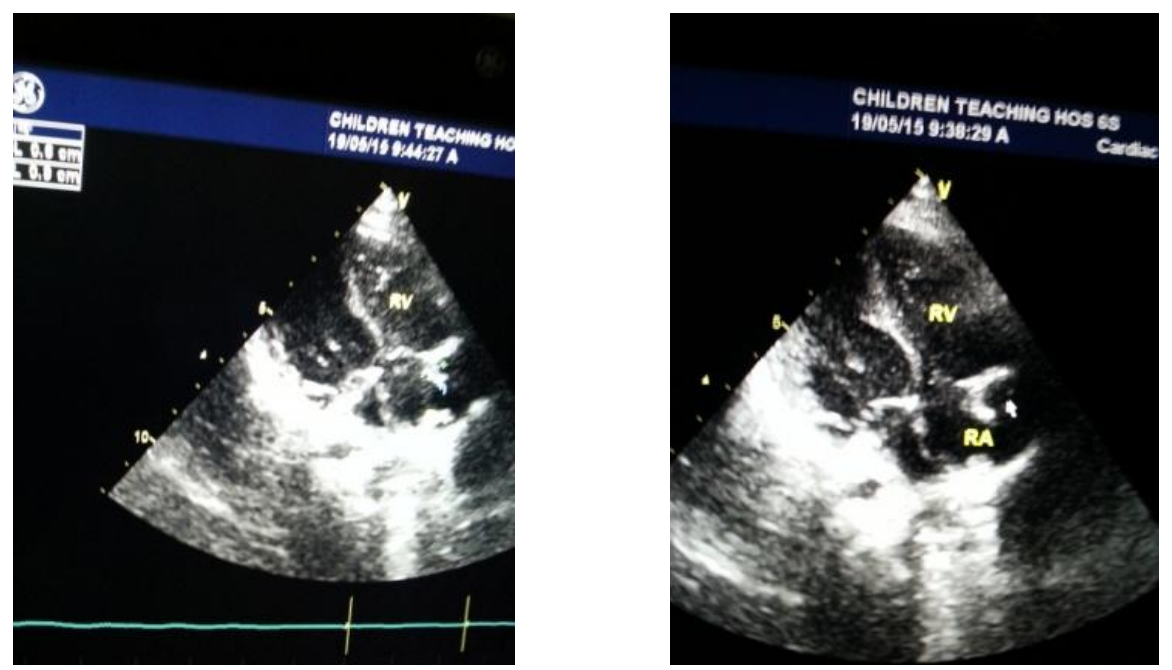

Figure 3:- Rt.aterial rhabdomyoma after Regression.

\section{Discussion:-}

In 1982, DeVore et al. first reported the prenatal diagnosis of a cardiac tumor. With the advancement of fetal echocardiography and magnetic resonance imaging (MRI), prenatal diagnosis of fetal cardiac tumors has become feasible, and the number of case series reported has increased in this past decade (2)

The earliest antenatal sonographic diagnosis of cardiac tumor was reported at 15 weeks of gestation(2)

Fetal cardiac rhabdomyomas are often benign and have a tendency to regress, but their prognosis is guarded due to very frequent association with arrhythmias and tuberous sclerosis (1).

The poor prognostic factors are:large tumors size,dysarrhythemia, the location of tumors.(2)

My patient was diagnosed with RT.aterial rhabdomyoma at the age of $21 \quad$ days ,she was sent to IBNALBETAR hospital for pericardiocenthesis for severe pericardial effusion for that she was put on prednisolon and frusemide for 4 weeks . follow-after a follow-up of 30 months the mass was regressed spontaneously .

This is the second case with cardiac rhabdomyma that undergo spontaneous regression in karballa Teaching Hospital for children,the first case was male before 7 years ago was diagnosed at age 45 days and complete regression was occurred at 5 years old.

Spontaneous regrerssion was reported in more than one study.in case report study at a mean follow-up of 47 months, they found that total or partial regression was observed in 7 patients .(1)

In another study of 77 cases diagnosed antenataly with rhabdomyoma and the patient were followed for 2 years they found that nine $(11.7 \%)$ had tumors that increased in size in utero, 18 remained unchanged, one regressed in utero and 49 (63.6\%) regressed in postnatal life.(2)

A study was done in Turkia they found that spontaneous regression occurs during the first $2-4$ years in $33 \%$ of cases(3)after amedian follow-up of 39 months of 6 cases with rhabdomyoma was diagnosed in the neonatal period(mean age was 16.8 days) ,2 patients had marked tumor regression and one had complete tumor regression.(3)

Even very large rhabdomyoma may regress spontaneously or complete disappearance of the mass occurs without intervention.(4)

So surgical treatment indicated in in special circumstances; when there is life threatening hemodynamic instability, intractable arrhythmia .(4) 
In summary ,I report a case of RT.aterial rhabdomyoma in 21days old neonate that regressed spontaneously after 30 months follow-up.

\section{Refernces:-}

1. Pipitone S, Mongiovì M, Grillo R, Gagliano S, Sperandeo V. Cardiac rhabdomyoma in intrauterine life: clinical features and natural history. A case series and review of published reports Italian Heart Journal : Official Journal of the Italian Federation of Cardiology [2002, 3(1):48-52]

2. A. S. Chao ${ }^{1, \dagger}$, A. Chao ${ }^{1, \dagger}$, T. H. Wang ${ }^{1}$ Y. C. Chang,- Y. L. Chang' C. C. Hsieh ${ }^{1}$ R. Lien $^{3}$ and W. J. $\mathrm{Su}^{3}$. Outcome of antenatally diagnosed cardiac rhabdomyoma: case series and a meta-analysis refrrence. Ultrasound in Obstetrics \& Gynecology .Volume 31, Issue 3, pages 289-295, March 2008

3. Kutluk T, Demir HA, Büyükpamukçu M, Özkutlu S, Akyüz C, Varan A, Yalçın . Cardiac rhabdomyomas in childhood: six cases from a single Institution. Turk J Pediatr 2013; 55: 69-73.

4. Gerald B.Marx,Adrian M.Moran:Cardiac Tumors,Moss \& Adams Heart Disease in Infant, Children,and Adolescents including Fetus and Adult,8 th Edition 2013,volum 2.

5. Daniel Bernstein:Tumors of The Heart,Nelson Text Book of Pediatrics, 18 th Edition.

6. Myung K.Park,R.George Troxler:Cardiac Tumors,Pediatric Cardiology for Practioners,4th Editon,chapter 22, page 321. 